\title{
Disaster Data Centre-An Innovative Educational Tool for Disaster Reduction through Education in Schools
}

\author{
Lekkas Efthymis ${ }^{1}$, Salachoris Michael ${ }^{2}$, Grambas Alexia1, Plessas Panagiotis ${ }^{2}$, \\ Alexoudi Vassiliki ${ }^{1}$, Valadaki Kate ${ }^{1}$, Plessas Spyros ${ }^{1}$ \\ ${ }^{1}$ Department of Dynamic, Tectonic and Applied Geology, Faculty of Geology and Geoenvironment, National \\ and Kapodistrian University of Athens, Athens, Greece \\ ${ }^{2}$ Geoset Consultants for the Development, GeoSet Ltd., Geolnformation Consulting Company, Athens, Greece \\ Email: ${ }^{*}$ elekkas@geol.uoa.gr
}

Received May 2014

\begin{abstract}
During the last decades, mankind has suffered from devastation caused by natural disasters and technological accidents of increased frequency and children are among the most vulnerable population group, especially those attending school during times of disaster. The importance of education in promoting and enabling disaster risk reduction has already been identified by researchers. In this paper "Disaster Date Center (DDC)" is presented, a new, powerful and innovative tool for the study of and education on disasters. One noteworthy application of DDC is the educational and public awareness tool in the form of e-learning.
\end{abstract}

\section{Keywords}

Disaster, Disaster Awareness, Disaster Reduction Education, e-Learning

\section{Introduction}

During the last decades, mankind has suffered from devastation caused by natural disasters and technological accidents of increased frequency. Intense recurrent phenomena all over the world, such as floods, earthquakes, landslides and tsunamis, caused by strong geotectonic rearrangements, indicate an accelerated process of reforming the earth's surface. Furthermore, an increase in the frequency of technological disasters is also apparent over the last years. Human activities and management failure result in large scale technological disasters, such as nuclear accidents, explosions, contamination from waste and toxic chemicals, biological contamination etc. These events are projected to be major issues for state and local authorities in the immediate future and a large number of scientists worldwide have started to systematically investigate them [1]. Thus, expertise and knowledge on this field is constantly accumulated worldwide.

When a natural hazard strikes, children are among the most vulnerable population group, especially those at-

"Corresponding author.

How to cite this paper: Efthymis, L., Michael, S., Alexia, G., Panagiotis, P., Vassiliki, A., Kate, V. and Spyros, P. (2014) Disaster Data Centre-An Innovative Educational Tool for Disaster Reduction through Education in Schools. Journal of Power and Energy Engineering, 2, 35-40. http://dx.doi.org/10.4236/jpee.2014.29006 
tending school in times of disaster. During disasters, school buildings are destroyed, taking away the precious lives of children and teachers and stalling access to education in the aftermath of disaster. Rebuilding these schools can take years and is very costly. Disasters such as the October 2005 earthquake in Pakistan, where over 16,000 children died in schools that collapsed, or the earthquake in Sichuan Province in the People's Republic of China in 2008, where more than 80.000 school children lost their lives while attending school, are just a few tragic examples of why more needs to be done to protect our children before disasters strikes [2].

Teaching children risk reduction and management skills is of great importance. Students of all ages can actively study and participate in school safety measures, and also work with teachers and other adults in the community towards minimizing risk before, during and after disastrous events. Furthermore, children traditionally spread their knowledge to their families and communities. Educating a child is often equivalent to educating a whole family. In this context, educational institutes, especially schools, constitute favorable environments for the dissemination of knowledge for disasters and disaster management. In this scope, appropriate training for teachers is the first step to disaster reduction education in school [3]-[5].

The National and Kapodistrian University of Athens (Greece) has developed a specialized e-learning course for educators in Greece, which focuses on disaster management in schools and utilizes an innovative service called Disaster Data Centre (DDC) to draw up-to-date data, information and references on recent major disasters in Greece and worldwide to be used as educational material. Efficient education on disaster management protection measures and dissemination of up-to-date disaster information can contribute to the reduction of its impact at schools. The innovative educational tool DDC has the unique ability to offer real-time information on disaster events.

After completing the course, it is expected that educators will be able to communicate the knowledge on disaster preparedness and management to children and their families, to participate in both pre and post disaster activities for preparedness and mitigation of disaster in schools, to respond timely and effectively through informed decision-making in the event of a disaster and to promote school building safety, all of which are key action points in the unfortunate event of a calamity [5] [6].

\section{The "Disaster Data Centre (DDC)" Service}

Currently, data on catastrophic events, regarding their cause, effect and management are collected, recorded, published, stored or archived by various public services responsible for preventing and managing disasters, the mass media, researchers, in scientific publications, local public or private entities and individuals who witnessed these events, or are somehow related to them. This accumulation of information, however, lacks structure and organization, thus fails to be channeled promptly to the authorities and society [6].

Disaster Data Centre (DDC) is a service which utilizes a modern and technologically advanced system in order to serve as an "Ark" which stores and preserves knowledge and information which may be lost or forgotten after the catastrophic events have taken place. The Disaster Data Centre stores and preserves the countless information (recent and older) related to catastrophic events, organized and presented in a scientific and innovative way, which allows easy retrieval of individual and combined information through queries. Emphasis has been given on interactive communication applications and direct communication of anyone interested. Separate applications enable the public to submit documents, audiovisual material, testimony and opinions about an event. The data entry is done through a special, user-friendly platform.

\subsection{Software Architecture}

An overview of the software architecture is presented in Figure 1.

The schema is divided in three layers: Web, Business and Data layer. Each layer acts as container of functionalities. In the schema right section there is a security block which is vertical present because security functionalities are layer-independent.

The web layer contains the web page which is responsible for the delivery and formatting of information to below layers for further processing or display. The web page in other words is the gate of users to our system. Through web page users can search, add or modify content based on security permissions that apply.

The business layer contains data management and external applications blocks. Data management is a system component that acts as intermediary between the upper software and the data. Data management exposes methods of managing the stored data without exposing or creating dependencies on the data storage mechanisms. 


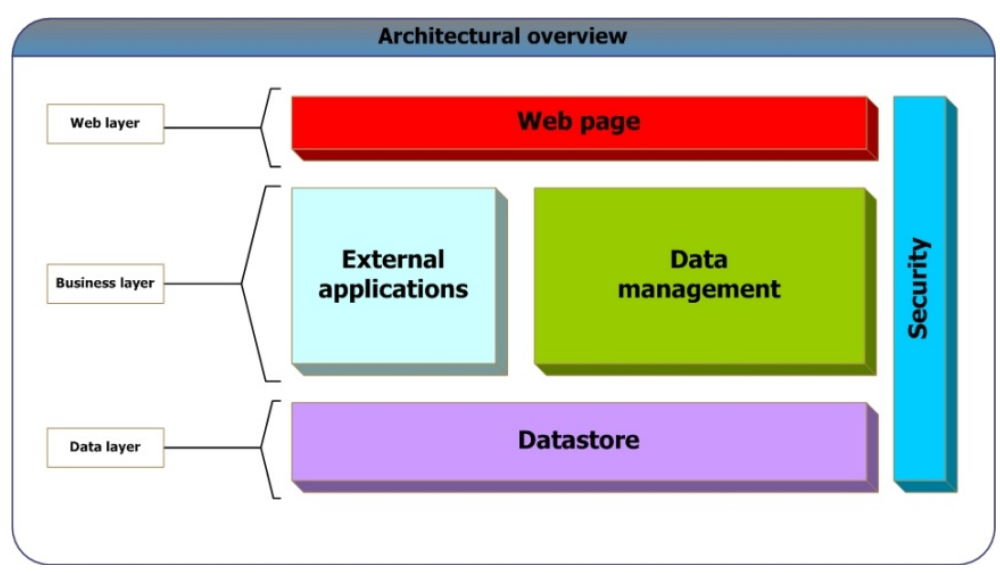

Figure 1. Overview of software architecture.

The retrieval, insertion or modification of data is consumed through this block. The external applications block describes the applications that interact with the system datastore through data management, but overall their operation has nothing to do with users. This type of software acts as an information gathering service, with a main purpose of searching and collecting information on a particular disaster over social networks.

The data layer is the base of the system and includes the data persistence mechanisms (database servers, file servers). A database is an organized collection of data. The data are typically organized to model relevant aspects of reality in a way that supports processes requiring this information. A file server is a computer attached to a network that has the primary purpose of providing a location for shared disk access.

\subsection{System architecture}

In Figure 2 the system architecture is presented. This section provides a more detailed description of disaster data center (DDC) system architecture based on the implementation.

Disaster data center as described on the previous chapter is based on multi-layer model architecture. In the above schema entities are colored according to architectural overview schema, so the web-layer contains the "www.ddc.com" block as the web page, the business layer contains "Web services API" as the data management and "Data collector" as external applications, and the data layer contains the "Website database" and "DDC datastore".

"www.ddc.com" is the website, which is a set of related web pages served from a single web domain, which in turn present the disaster information to users. It is built with Joomla! context management system.

Web services API is a collection of web services that interact with the database and act as middleware between "www.ddc.com" and DDC-datastore. A Web service is a method of communications between two electronic devices over the World Wide Web. It is a software function provided at a network address over the web with the service always on as in the concept of utility computing. The web service API is built with Java using REST architectural style which allows interaction with a web-based system via simplified URL's.

Data collector is the software that gathers data over social networks like Facebook, Twitter and YouTube. Every event is defined by metadata which some of them are the keywords for additional searching and information gathering. The data collector application will be designed with time based rules so the information search applies to the social network restrictions. The data collection service will be implemented in Java.

\section{3. e-Learning Tool}

One noteworthy application is the educational and public awareness tool in the form of e-learning. The web service is based on the principles of open communication and is offered without cost to the general public. The Laboratory for the Study and Management of Natural Disasters of the National University of Athens, Greece (NUA) has developed, after appropriate processing of the Disaster Data Centre's specific educational content, e-learning courses addressed to scientists, government officials, civil protection officials, law enforcement officials, business executives, members of voluntary organizations, teachers and students at all levels, etc., with interest in preventing and managing the Natural and Technological disasters. 


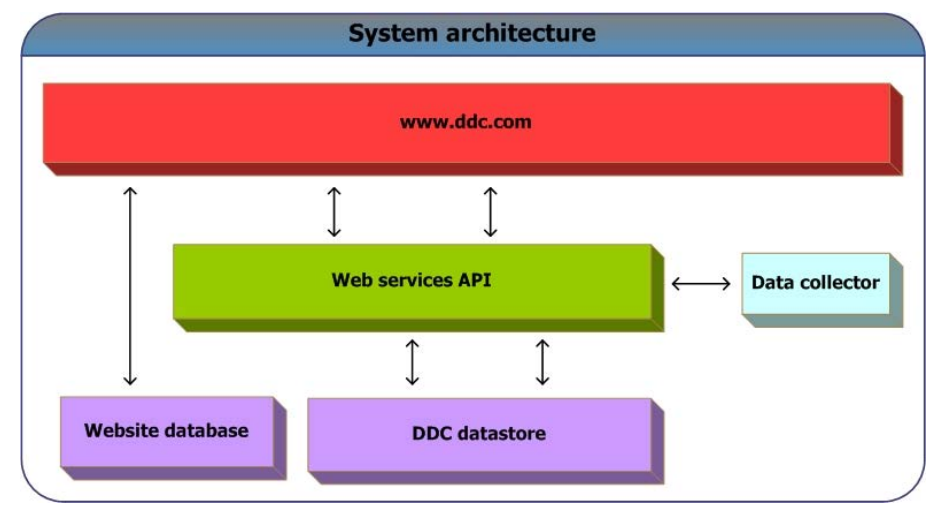

Figure 2. Overview of system architecture.

\section{Disaster Reduction Education for School Teachers}

The necessity of disaster reduction education in schools is unambiguous [4] [7]. Only in the last decade more than 100,000 children have lost their lives while at school during disaster events, and hundred thousands more have been injured physically and psychologically (Figures 3-5) [5].

The Laboratory for the Study and Management of Natural Disasters of the National University of Athens (NUA) has developed an e-learning course which includes the following topics:

- Hazards and Disasters: Introduction to the concepts of disasters (geodynamic disasters, hydrometeorological disasters, biological disasters, technological disasters), major disasters worldwide, disasters in Greece, impact of disasters to school environments.

- Prevention and mitigation of disaster impact to school environments: Civil protection, School and community disaster management planning, reinforcement of schools, student safety and protection, prevention and protection measures.

- Educating students - the role of the teacher in the disaster reduction education in schools: Planning courses according to the students' age, planning mock drills, psychological issues, consulting and guidelines for student support.

The course utilizes numerous case studies, current, recent and older, drawn from the DDC database. Numerous quizzes and assignments have been included to the course, not only to allow for the participants to evaluate their own progress, but also to evaluate and upgrade the course in general in order to answer the needs of school educators more efficiently and to upgrade the DDC services as well.

The course is conducted in the form of e-learning. One of the chief benefits of developing the e-learning curricula is the potential for ease of reuse and adaptation of e-learning content. This requires development of a learning object repository sharing standards-compliant content which is facilitated by the use of the DDC services.

It has been proved that students in online learning have actually performed better than those in face-to-face courses. The main benefits of e-learning for students are flexible access, 24/7, to study materials, the option of self-paced learning which accommodates individual requirements, the availability of text, audio and video which accommodates different learning modalities and the very low cost per student [7].

\section{Discussion-Expected Results}

The pilot operation of the e-learning tool provided by the DDC will take place in October 2014. A class of 25 K-12 educators will be formed who will complete the course within 8 weeks. The evaluation phase will follow and the results of the pilot operation will be demonstrated soon after the evaluation phase is completed.

It is expected that:

- More than $90 \%$ of the educators will successfully complete the course.

- More than $90 \%$ of the educators will evaluate the course positively.

- More than $60 \%$ of the educators will give useful feedback for upgrading the course.

- More than $90 \%$ of the educators will state that, after completing the course, they feel more confident to cope with a disaster than before. 

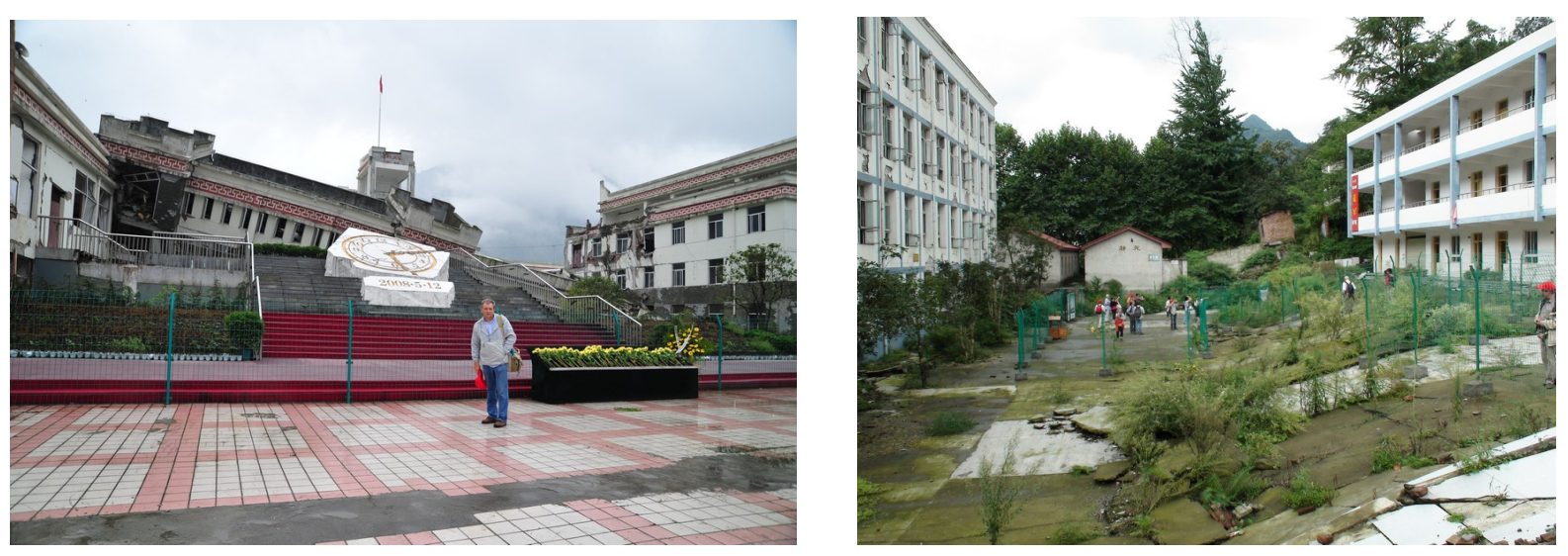

Figure 3. Remains of school facilities that collapse after the great earthquake of $12^{\text {th }}$ May 2008 in Sichuan Province, China. A monument was built as a reminder of the devastation.
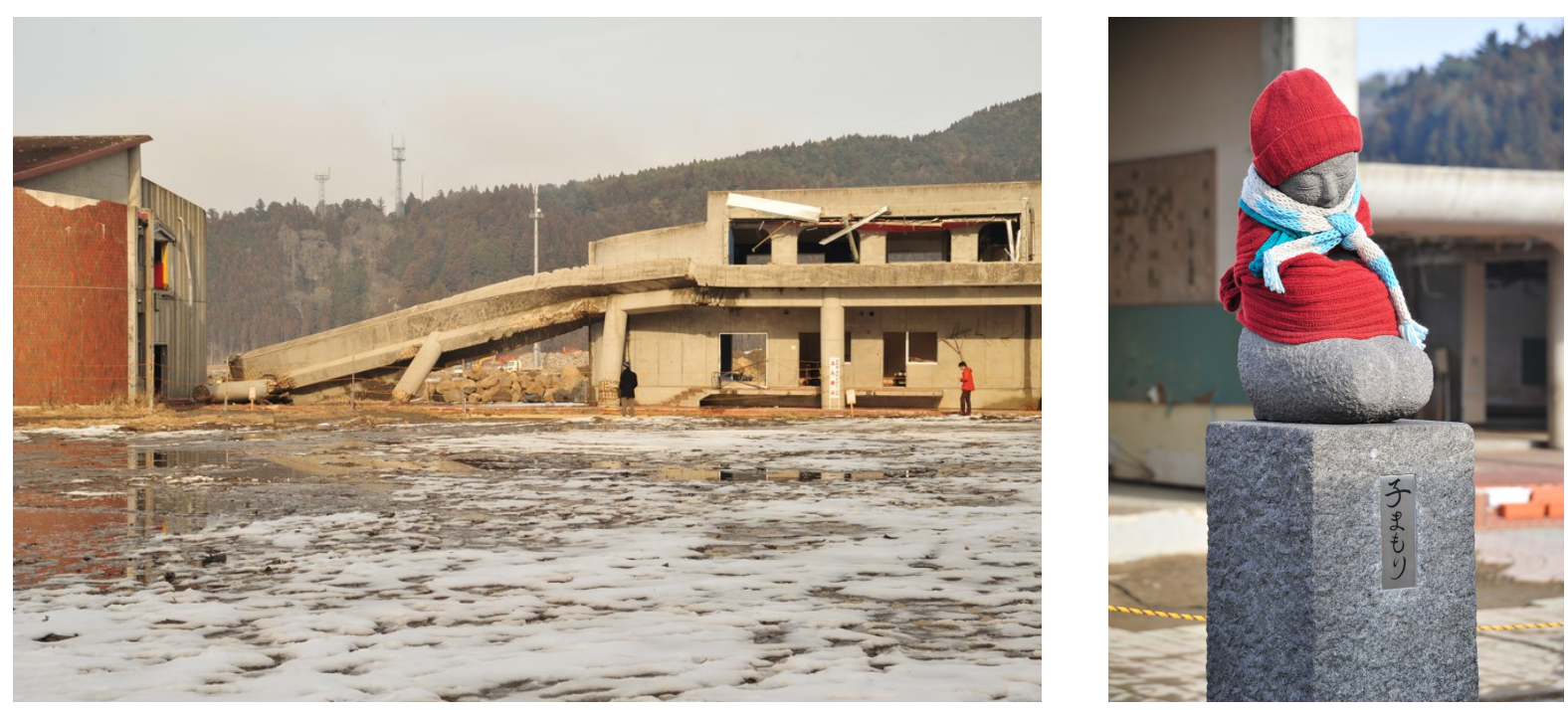

Figure 4. Remains of school facilities after the tsunami of $11^{\text {th }}$ March 2011 that stroke NE Japan. The evacuation plan failed resulting in the death of many small children. The statue was placed a reminder.
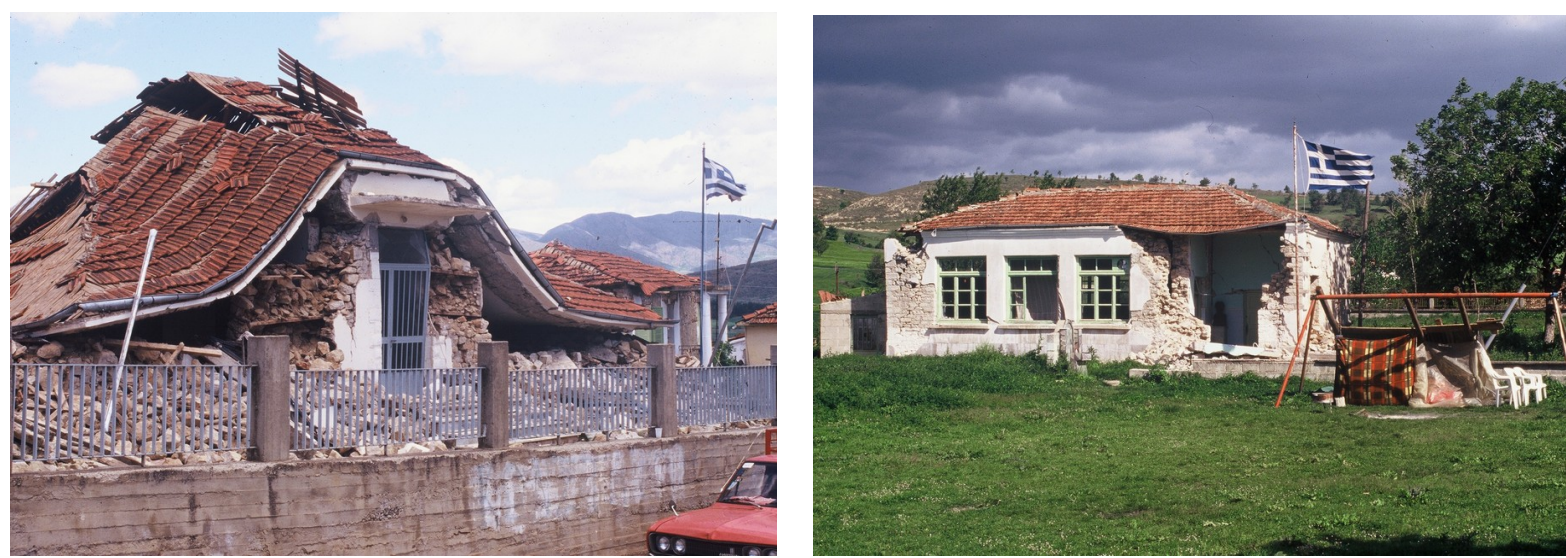

Figure 5. Remains of school buildings that collapsed after the earthquake of $12^{\text {th }}$ May 1995 in Grevena Province, Greece.

- More than $70 \%$ of the educators will plan a mock drill customized to fit their school's particularity and environment. 
- More than $80 \%$ of the educators will plan a disaster awareness course for their students, accommodated to their age and needs.

- More than $60 \%$ of the educators will plan a disaster awareness informative session for the parents.

- More than $70 \%$ of the educators will make suggestions for their school's reinforcement to the school council. It should be noted that the DDC software and services can easily be adopted by other countries. It currently hosts information in Greek and English but it has been designed to embed any language.

\section{References}

[1] Birkmann, J. (2006) Measuring Vulnerability to Natural Hazards. United Nations University, New Delhi.

[2] Wisner, B. (2006) Let Our Children Teach Us. A Review of the Role of Education and Knowledge in Disaster Risk Reduction. Books for Change.

[3] McClure, J., Walkey, F. and Allen, M. (1999) When Earthquake Damage Is Seen as Preventable: Attributions, Locus of Control and Attitudes to Risk. Applied Psychology: An International Review, 48, 239-256. http://dx.doi.org/10.1111/j.1464-0597.1999.tb00060.x

[4] Mishra, S. and Suar, D. (2007) Do Lessons People Learn Determine Disaster Cognition and Preparedness? Psychology Developing Societies, 19, 143. http://dx.doi.org/10.1177/097133360701900201

[5] Shaw, R., Shuwaku, K. and Takeuchi, Y. (2011) Community, Environment and Disaster Risk Management, Volume 7 Disaster Education. 1st Edition, Emerald Group Publishing Ltd., Bingley.

[6] Eiser, J.R., Bostrom, A. and Burton, I. (2012) Risk Interpretation and Action: A Conceptual Framework for Responses to Natural Hazards. International Journal of Disaster Risk Reduction, 1, 5-16. http://dx.doi.org/10.1016/j.ijdrr.2012.05.002

[7] International Federation of Red Cross and Red Crescent Societies (2011) Public Awareness and Public Education for Disaster Risk Reduction: A Guide. 302200 E 06/2011. 